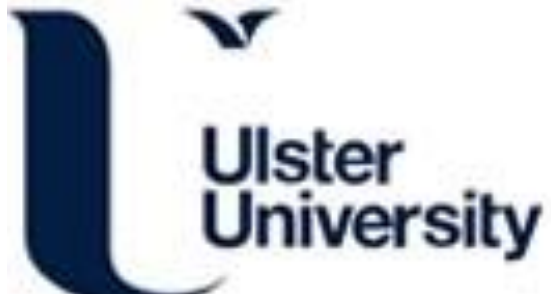

Predicting the development of asphalt surfacing properties in Ireland

Friel, S., \& Woodward, D. (2013). Predicting the development of asphalt surfacing properties in Ireland. In Unknown Host Publication (pp. 829-840). American Society of Civil Engineers.

Link to publication record in Ulster University Research Portal

\section{Published in:}

Unknown Host Publication

Publication Status:

Published (in print/issue): 01/01/2013

\section{Document Version}

Publisher's PDF, also known as Version of record

\section{General rights}

Copyright for the publications made accessible via Ulster University's Research Portal is retained by the author(s) and / or other copyright owners and it is a condition of accessing these publications that users recognise and abide by the legal requirements associated with these rights.

\section{Take down policy}

The Research Portal is Ulster University's institutional repository that provides access to Ulster's research outputs. Every effort has been made to ensure that content in the Research Portal does not infringe any person's rights, or applicable UK laws. If you discover content in the Research Portal that you believe breaches copyright or violates any law, please contact pure-support@ulster.ac.uk. 


\title{
Predicting the development of asphalt surfacing properties in Ireland
}

\author{
Shaun Friel ${ }^{1}$ and David Woodward ${ }^{2}$ \\ ${ }^{1}$ University of Ulster, School of the Built Environment, Jordanstown, Shore Road, \\ Newtownabbey, Co. Antrim, Northern Ireland; email: friel-s3@email.ulster.ac.uk \\ ${ }^{2}$ University of Ulster, School of the Built Environment, Jordanstown, Shore Road, \\ Newtownabbey, Co. Antrim, Northern Ireland; email: wdh.woodward@ulster.ac.uk
}

\begin{abstract}
:
This paper gives an over-view of research into predicting the development of asphalt surfacing properties for mixes used in Ireland. Accelerated trafficking was simulated using the Road Test Machine. The asphalt materials included asphalt concrete, hot rolled asphalt, stone mastic asphalt; and proprietary high friction surfacing and thin surfacing systems. The properties assessed include wet skid resistance, aggregate exposure, 2D and 3D areal texture. The findings highlight the role of aggregate and bitumen type; nominal particle size and bitumen properties. The results show that properties such as skid resistance can be optimised for a given aggregate depending on how it's used. It suggests that lower skid resistant aggregate can be used as a smaller nominal size and still provide adequate levels of in-service performance. The data suggests that current specifications could be modified to allow better optimisation / more sustainable use of local aggregates than previously allowed.
\end{abstract}

\section{INTRODUCTION}

Ireland has a diverse geology and a wide range of rock-types that can be used in highway construction. Specifications in the UK require what may be termed High Specification Aggregates (HSA) for the surfacing layer (Thompson et al., 2004). HSA aggregate must have high levels of skid resistance as well as all the other aggregate properties of size, shape, strength, abrasion and soundness. As a construction material HSA is expensive with a relatively high carbon footprint. The asphalt industry now accepts that sustainability i.e. ranging from the technologies used to how materials are specified, is here to stay. Options exist such as greater use of recycling of old roads. Another is to use local aggregates that may not meet the existing requirements of HSA but which provide levels of performance that do not compromise safety, comfort for the road user and long-term durability. There are many issues to consider when trying to understand the performance of asphalt surfacing materials. Ideally, this needs to consider not only the asphalt mix, but more importantly how the trafficked surface of the asphalt mix interacts with a moving tire. In terms of wet skidding resistance, current European material specifications and 
guidelines have evolved using the measurement of mix components such as aggregate PSV or bitumen grade. This does not allow optimisation based on mix performance. Rather, one must consider assessing the asphalt mix in its entirety and not its individual components. There is the need to relate what happens in the real world to laboratory testing.

A holistic approach is required along with consideration of in-service expectations throughout design life. Depending on site conditions, this will require the balancing of differing and possibly conflicting properties. At present, there is a perception that wet skid resistance is the most important property in Ireland and the $\mathrm{UK}$ as this relates to safety of the road user. However, are other properties such as noise, spray, rutting, cracking, ravelling and durability of equal / or more importance as they are needed to optimise performance and maximise design life. This paper gives an over-view of research into predicting the development of asphalt surfacing properties for mixes used in Ireland and the United Kingdom. Accelerated trafficking was simulated using the Road Test Machine (Nicholls, 1997). The asphalt materials included asphalt concrete, hot rolled asphalt, stone mastic asphalt; and proprietary high friction surfacing and thin surfacing systems. The properties reported in this paper are wet skid resistance and texture depth. Using the interaction of a real tire with the different materials under controlled laboratory conditions has allowed a ranking of materials to be developed. Repeated testing during simulated trafficking allows insight into how the measured properties evolve with time.

\section{MATERIALS ASSESSED}

A wide range of asphalt materials are reported in this paper. They can be grouped into a number of generic types i.e. asphalt concrete (AC) (NSAI, 2006a), hot rolled asphalt (HRA) (NSAI, 2006b), stone mastic asphalt (SMA) (NSAI, 2006c), proprietary thin surfacing systems (TS) and high friction surfacing systems (HFS) (BBA, 2011). The nominal sizes range from 3mm HFS; $6 \mathrm{~mm}, 10 \mathrm{~mm}$ and $14 \mathrm{~mm}$ SMA; $14 \mathrm{~mm}$ and $20 \mathrm{~mm}$ AC to HRA with $20 \mathrm{~mm}$ pre-coated chippings. The rock types include Carboniferous limestone, Tertiary basalt and Silurian greywacke. The bitumen's ranged from 50 - 200pen grade to polymer modified grades.

\section{PREPARATION OF TEST SPECIMENS}

All testing reported in this paper was carried out on materials that would be used in-service in Ireland and the UK. In most cases, asphalt was sampled at mixing plants and re-heated to create roller compacted 305 x 305 x 50mm test specimens. In certain cases, graded aggregate was mixed with bitumen in the laboratory prior to making roller compacted test specimens. The HFS test specimens were prepared by covering test specimens of 10mm SMA with an epoxy extended binder and applying the $3 \mathrm{~mm}$ aggregate. 


\section{ACCELERATED SIMULATED TRAFFICKING}

In Europe the Wehner Schulze test method (Woodbridge \& Dunford, 2006) is currently being considered as the European standard method to assess aggregate and asphalt mixes for skid resistance. However, this paper considers the assessment of test specimens subjected to simulated trafficking using the Road Test Machine (RTM). Unlike other test equipment such as PSV and Wehner Schulze, the RTM uses two full-size tires to simulate trafficking. The PSV, Wehner Schulze and RTM test equipment are shown in Figures 1, 2 and 3 respectively.

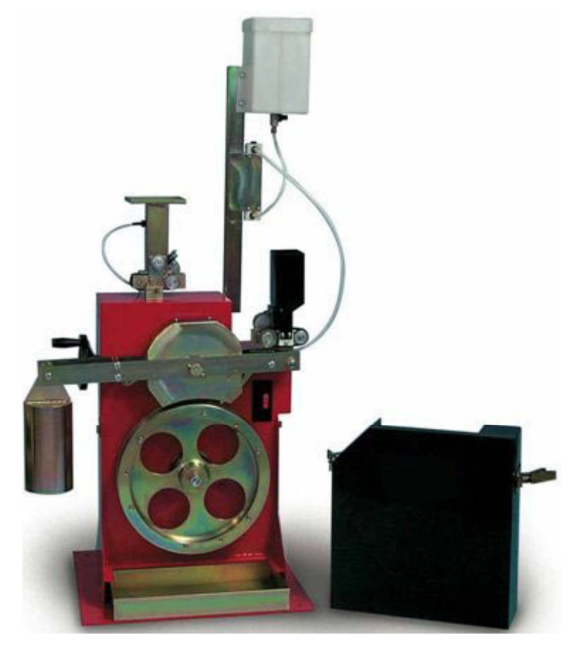

Figure 1. Accelerated polishing machine for PSV test

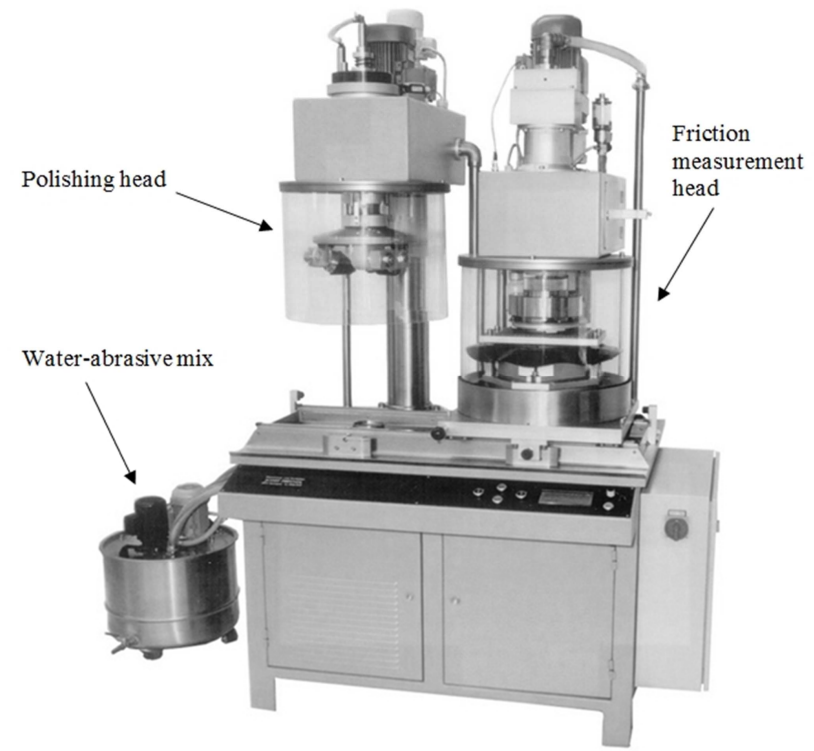

Figure 2. Wehner Schulze equipment 


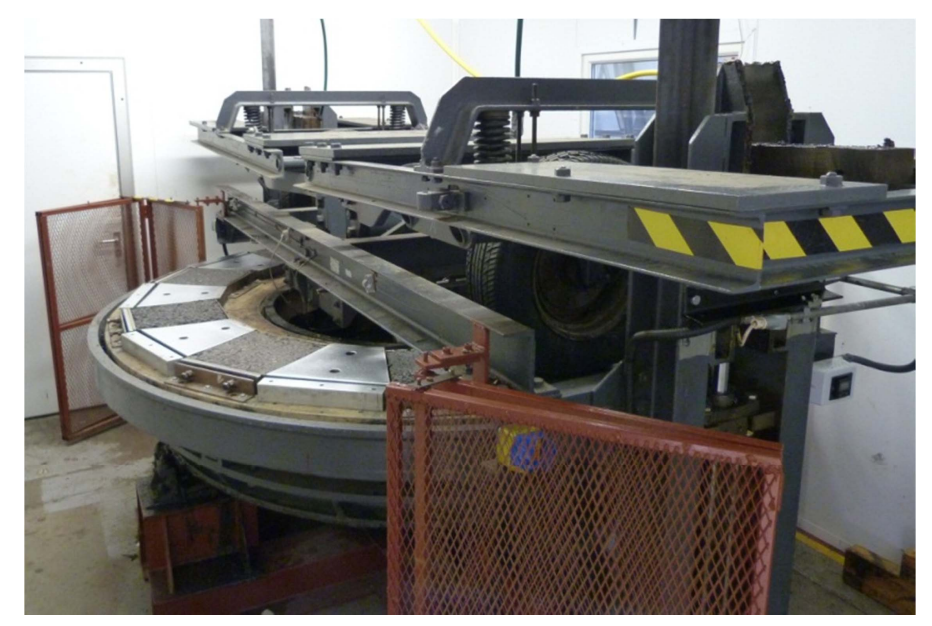

Figure 3. The Road Test Machine (RTM)

The RTM equipment is shown in Figure 3. It consists of a $2.1 \mathrm{~m}$ diameter table that rotates at $10 \mathrm{rpm}$ or $1.1 \mathrm{~m} / \mathrm{s}$. Up to ten $305 \mathrm{~mm} \times 305 \mathrm{~mm} \times 50 \mathrm{~mm}$ test specimens can be mounted on this table. Two vertically mounted Federal 195/70R14 tires run freely on the table, applying a load of approximately $5 \mathrm{kN}$ each. This simulates high stress within the contact patch. The tires track back and forth across the width of the test specimen generating additional stress. The RTM is enclosed in a temperature controlled room where testing is carried out at $10+/-2^{0} \mathrm{C}$. Simulated trafficking is stopped at regular intervals and each test specimen is assessed for change in a range of properties such as wet skidding resistance and texture depth using the British pendulum (PTV) and sand patch test methods respectively.

\section{DEVELOPMENT OF WET SKIDDING RESISTANCE AND TEXTURE DEPTH}

Figure 4 plots wet skidding data for all test specimens assessed using the RTM. This plots change in wet skid resistance as Pendulum Test Value (PTV) measured using the British pendulum (NSAI, 2011c). Similar to SCRIM (BSi, 2006) and GripTester (BSi, 2000) data measurements of highway surfaces, the laboratory data shows variation in early life development with increasing number of wheel passes. SCRIM (Sideways Force Routine Investigation Machine) measurement forms the basis of the Irish (NRA, 2011a) and UK skid resistance specification (DMRB, 2004). The RTM data then achieves equilibrium in relation to the standardised laboratory conditions of load, speed and temperature, as would be expected inservice.

The RTM data shows a range in wet skidding resistance of approximately 4550 PTV points during RTM simulated trafficking. This range is present both at the start of testing and at the end of testing and is dependent on factors such as rock type, asphalt mix type, aggregate nominal size, bitumen content and bitumen type. 


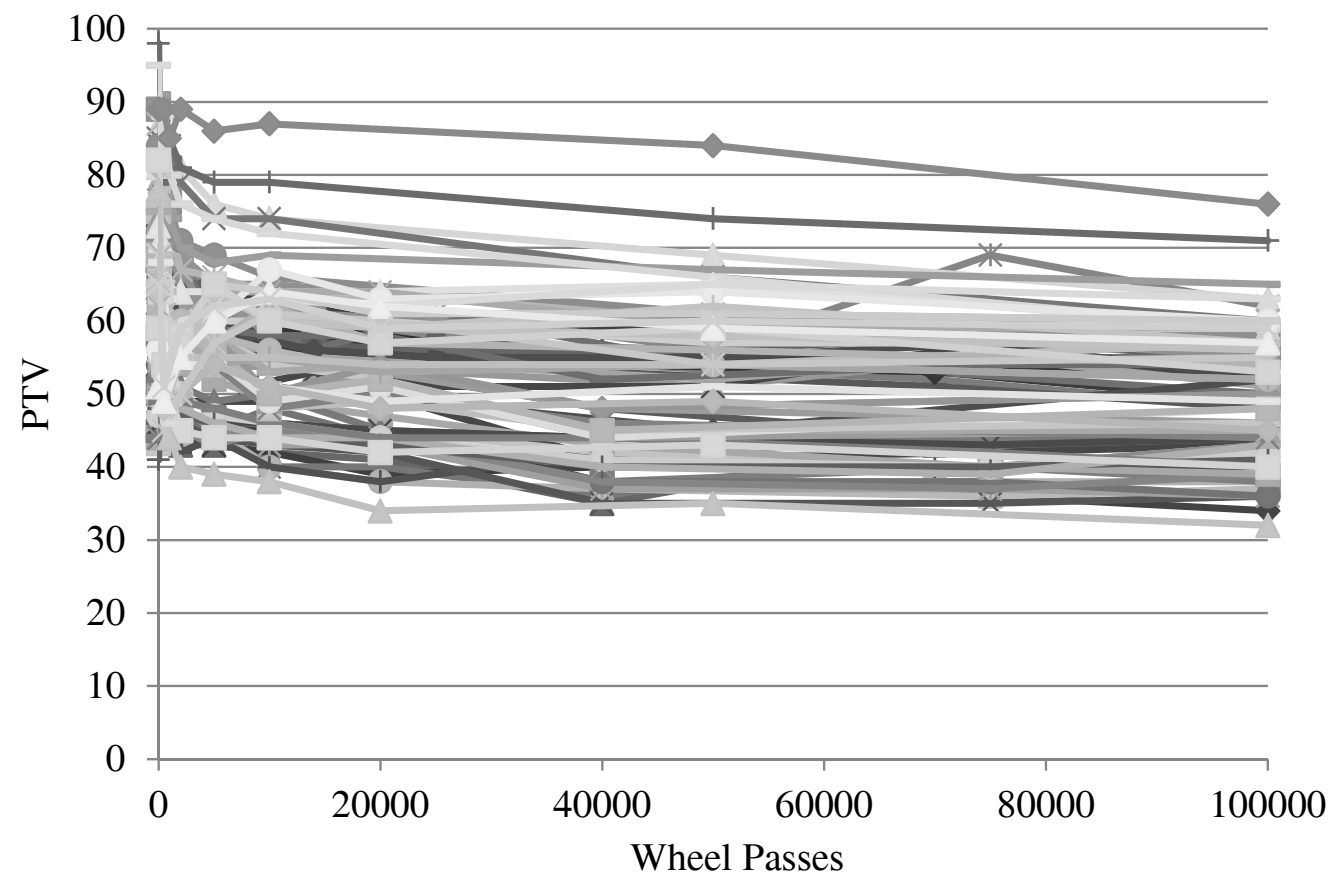

Figure 4. Development of PTV with increasing number of wheel passes - all data

Figure 5 simplifies this data by plotting averages based on rock type and asphalt type. The RTM data shows good agreement in order of PTV ranking for the different materials with what would be expected in-service. There are four groupings of data based on surfacing type and rock type. The best performing group with highest values of PTV relate to HFS made with $3 \mathrm{~mm}$ aggregate. The highest performing HFS is made with calcined bauxite, which in-service provides the best skid resistance possible of any surfacing type. Next highest is a HFS made with a natural sandstone aggregate. The second group of data relates to $6 \mathrm{~mm}, 10 \mathrm{~mm}$ and $14 \mathrm{~mm}$ SMA and HRA with $20 \mathrm{~mm}$ chippings. All these mixes were made with greywacke aggregate with PSV 60 to 68 . The third group of data is $14 \mathrm{~mm}$ AC made with basalt aggregate with PSV 55. The fourth group of data is $14 \mathrm{~mm}$ and $20 \mathrm{~mm} \mathrm{AC}$ made with limestone aggregate.

This simplified grouping of asphalt types shows that the RTM is able to rank mixes similar to what is measured on-site giving confidence in the method. The groupings also reflect PSV of the aggregates used in the mixes. Figure 6 plots the development of the same groupings based on texture depth measured using the sand patch test (NSAI, 2010b). In general the data shows a small loss in texture at the start of testing followed by equilibrium. There are three main groupings. The highest textured materials are the two HFS surfacings. The second grouping includes the $14 \mathrm{~mm}$ SMA, HRA with $20 \mathrm{~mm}$ chippings, $14 \mathrm{~mm}$ AC and 10mm SMA. The third grouping with lowest texture depth is the $20 \mathrm{~mm}$ AC and 6mm SMA. Again, this ranking of mix types based on texture depth would be expected in-service. 


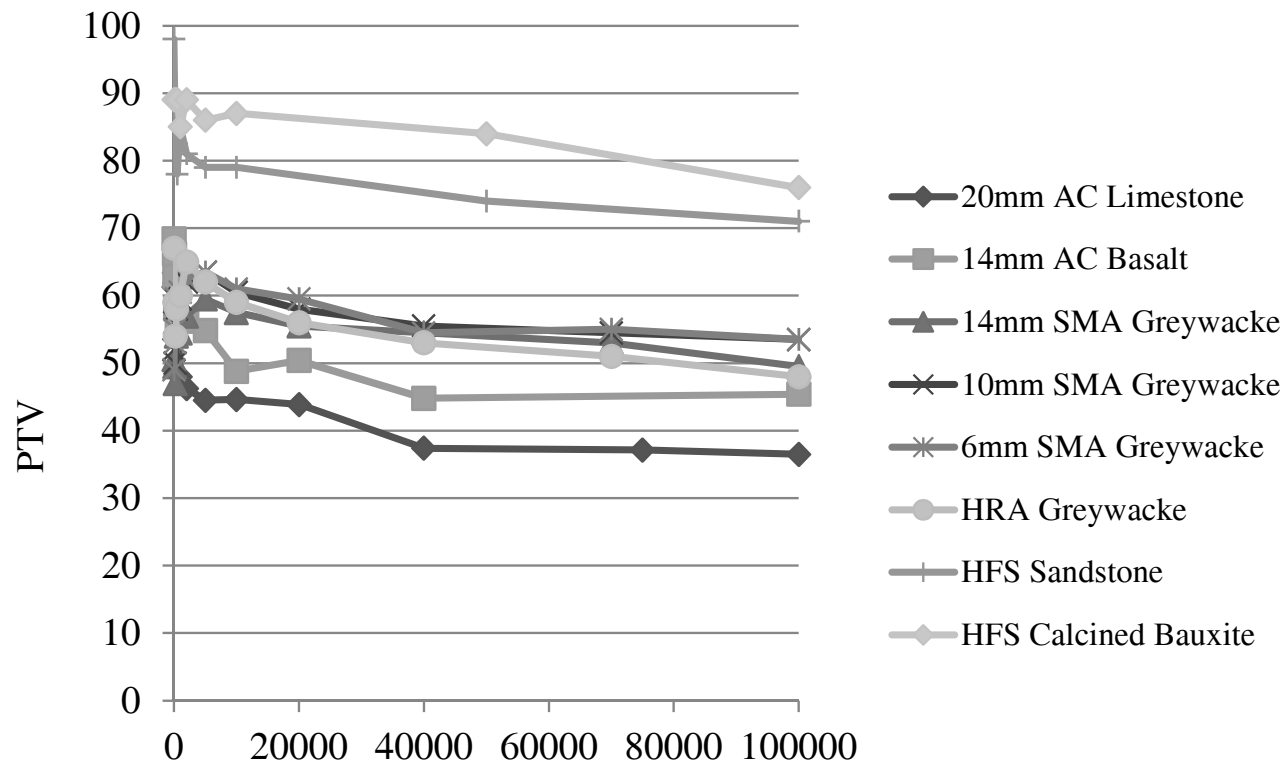

Wheel Passes

Figure 5. Simplified grouping of PTV data

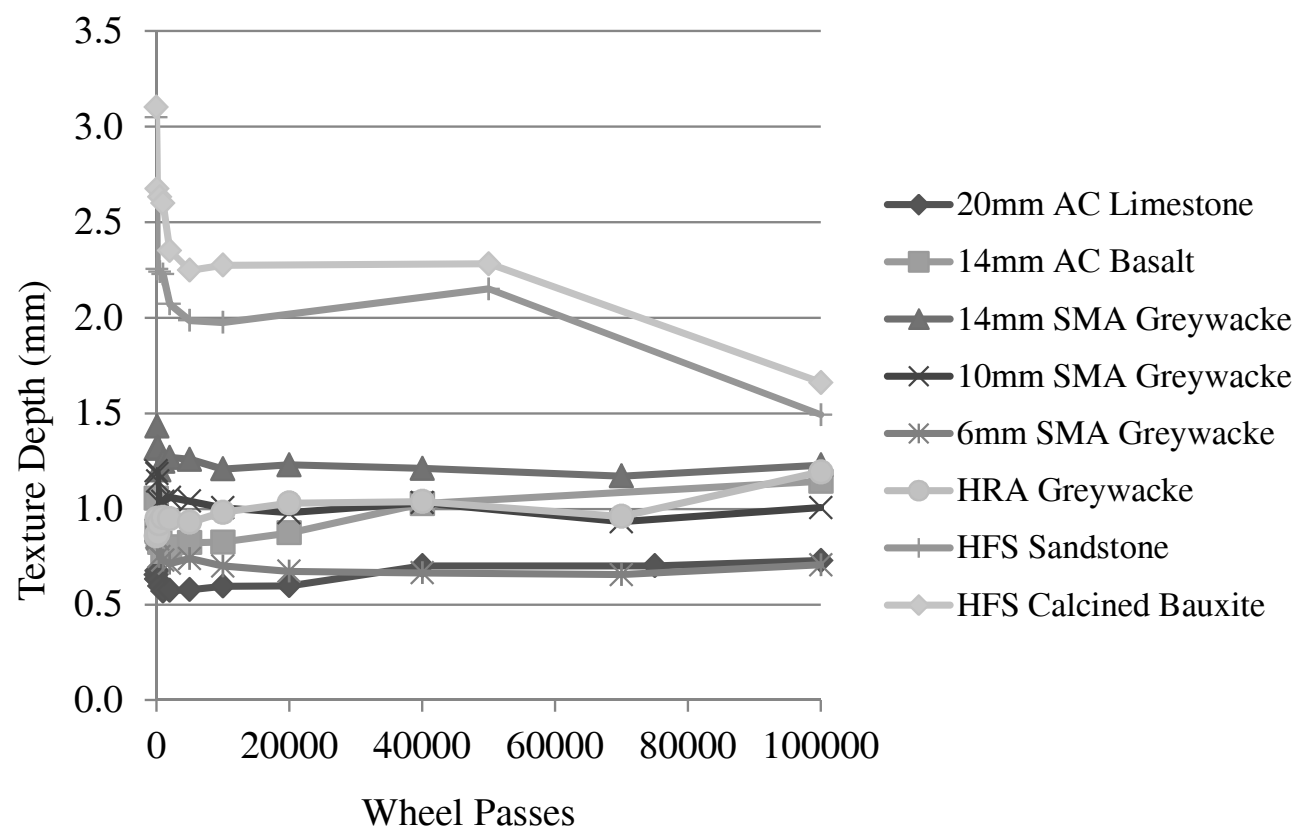

Figure 6. Simplified grouping of texture depth data - sand patch method 


\section{OPTIMISING MIX PROPERTIES}

RTM testing of $305 \times 305 \times 50 \mathrm{~mm}$ test specimens allows evaluation of different mixes in controlled laboratory conditions in short periods of time at low cost. The alternative is expensive, time consuming full-scale road trials that need years to provide meaningful data. 100,000 wheel passes in the RTM is equivalent to 5 to 10 years trafficking (BBA, 2008). So, having established that RTM testing can provide rankings of skid and texture data comparable with in-service data, the following examples show how materials and mix properties can be better optimised. Figures 7 and 8 consider the example of $6 \mathrm{~mm}, 10 \mathrm{~mm}$ and $14 \mathrm{~mm}$ SMA mixes made with greywacke aggregate with a high polished stone value (PSV) of 62 (NSAI, 2009).

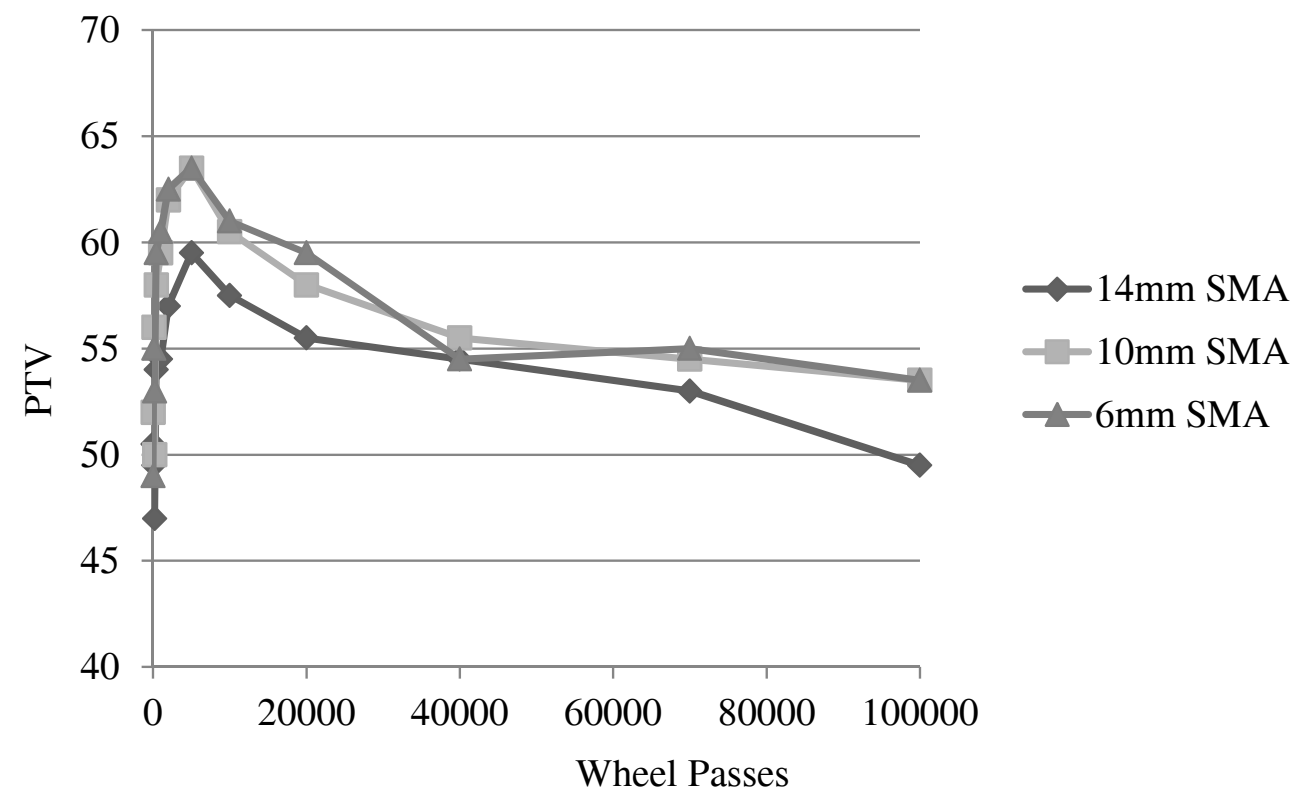

Figure 7. Development of PTV for $6 \mathrm{~mm}, 10 \mathrm{~mm}$ and $14 \mathrm{~mm}$ SMA

Figure 7 shows an initial increase in PTV during the early life of simulated trafficking on the RTM for all three mixes reaching a maximum value at 5,000 wheel passes. During this period the bitumen coatings on individual trafficked aggregate surfaces was removed exposing the aggregate micro-texture. After 5,000 wheel passes this trafficked aggregate starts to become polished as shown by the reduction in PTV value. The $14 \mathrm{~mm}$ SMA had lower values of wet skid resistance compared to the $6 \mathrm{~mm}$ and $10 \mathrm{~mm}$ that remained similar throughout testing. Using aggregate in smaller nominal size mixes increases the amount of aggregate potentially in contact with a tire i.e. as reflected by the pendulum slider / asphalt interaction. This property is now well documented in SCRIM and GripTester investigations (Roe et al., 2008). RTM testing to 100,000 wheel-passes show both the $6 \mathrm{~mm}$ and $10 \mathrm{~mm}$ SMA mixes to have reached approximate equilibrium conditions at 40,000 wheel passes. In comparison, the $14 \mathrm{~mm}$ SMA mix has not reached equilibrium and still appears to be polishing at 100,000 wheel passes. This possibly reflects more interaction at the tire / 
asphalt mix interface due to lesser available aggregate contact i.e. there may be a critical nominal aggregate particle size that is related to equilibrium skidding conditions.

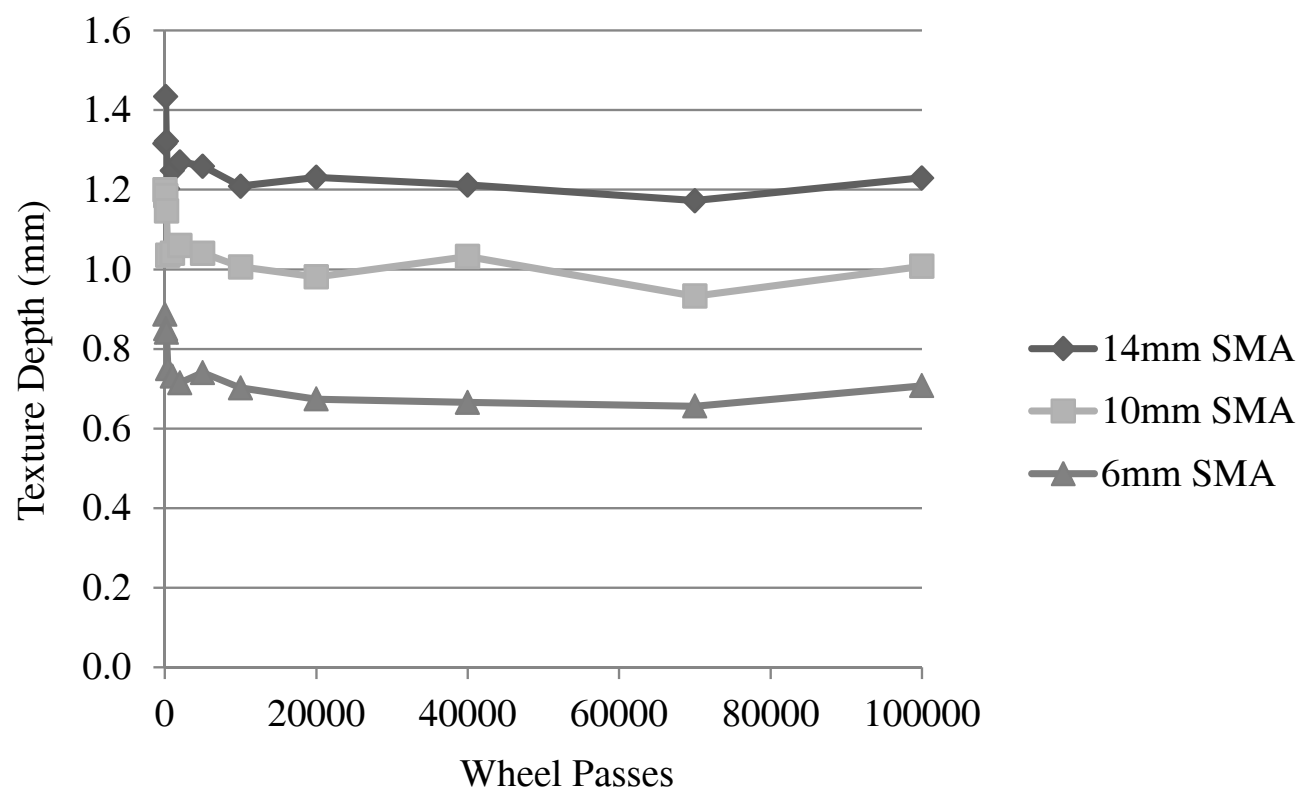

Figure 8. Development of texture depth for $6 \mathrm{~mm}, 10 \mathrm{~mm}$ and $14 \mathrm{~mm}$ SMA - sand patch data

Figure 8 plots the development of texture depth for the three SMA mixes. The relationship between nominal particle size and texture is apparent. As found inservice, the mixes with the larger nominal aggregate sizes have the higher texture depths. There is some initial reduction after which the three mixes had minimal change in texture depth. This indicates durable mixes able to withstand pro-longed high levels of stressing without loss of texture due to embedment or increase in texture due to surface ravelling.

Figures 9 and 10 consider the example of Hot Rolled Asphalt (HRA) and $20 \mathrm{~mm}$ greywacke aggregate chippings with PSV 62. Increasing amounts of $20 \mathrm{~mm}$ chippings were rolled unto the still hot HRA mastic to give increasing levels of texture depth. The test specimen with $20 \mathrm{~mm}$ chipping application rate of $12 \mathrm{~kg} / \mathrm{m}^{2}$ represents a typical rate of spread used in Ireland the UK for this greywacke aggregate. The $16 \mathrm{~kg} / \mathrm{m}^{2}$ test specimen represents an over-chipped surface i.e. one with excessively high texture depth that would be noisy when trafficked. The $10 \mathrm{~kg} / \mathrm{m}^{2}$ test specimen represents an under-chipped surface where the tire would be running on the mortar surface and in wet conditions there may be insufficient drainage to allow for the optimal removal of water. The unchipped HRA test specimen has no $20 \mathrm{~mm}$ pre-coated chippings applied to the HRA mortar. This has no macro-texture and any skid resistance relies on tire interaction with its relatively smooth surface roughness. The HRA test specimens reach their maximum PTV 
values at 2,000 wheel passes. In comparison the SMA mixes reached maximum values after 5,000 wheel-passes. This reflects a number of issues. For example, the aggregates in the SMA are enclosed in a relatively thick bitumen coating.

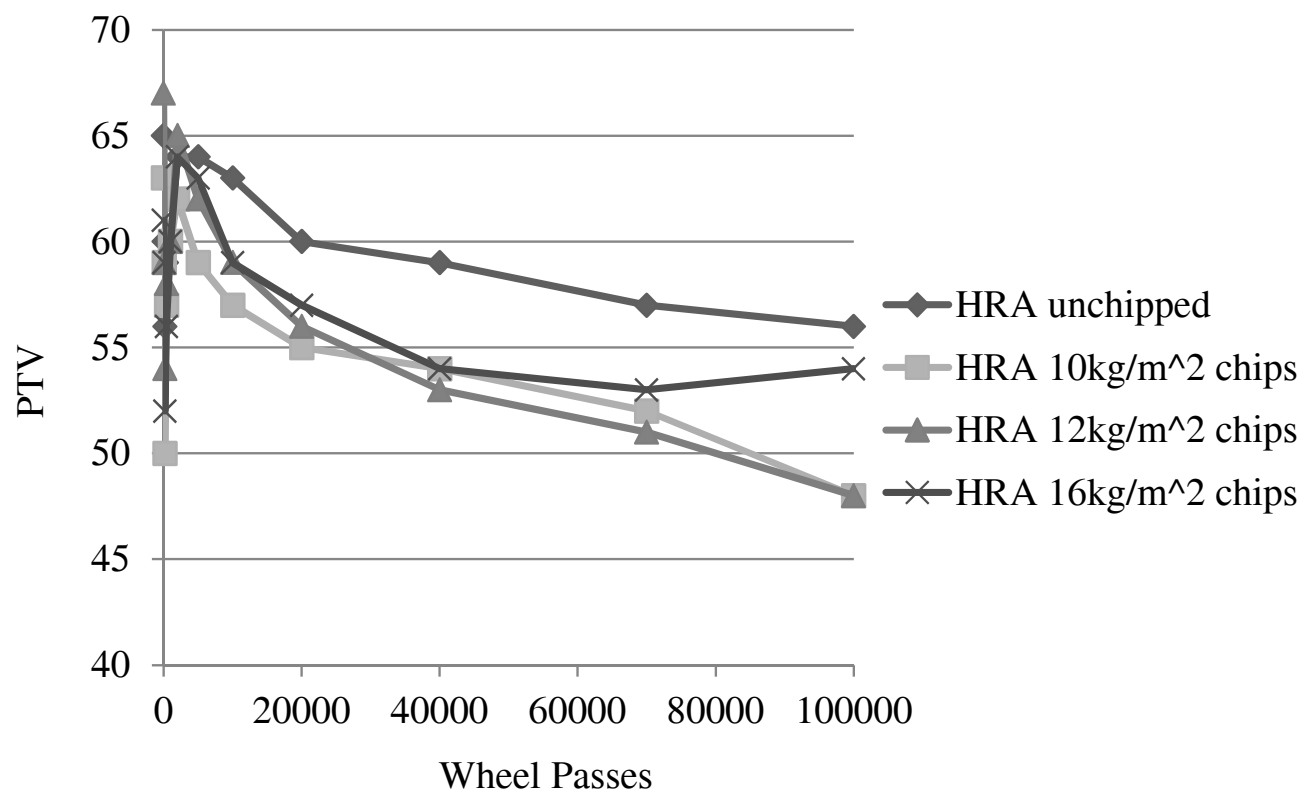

Figure 9. Development of PTV for HRA

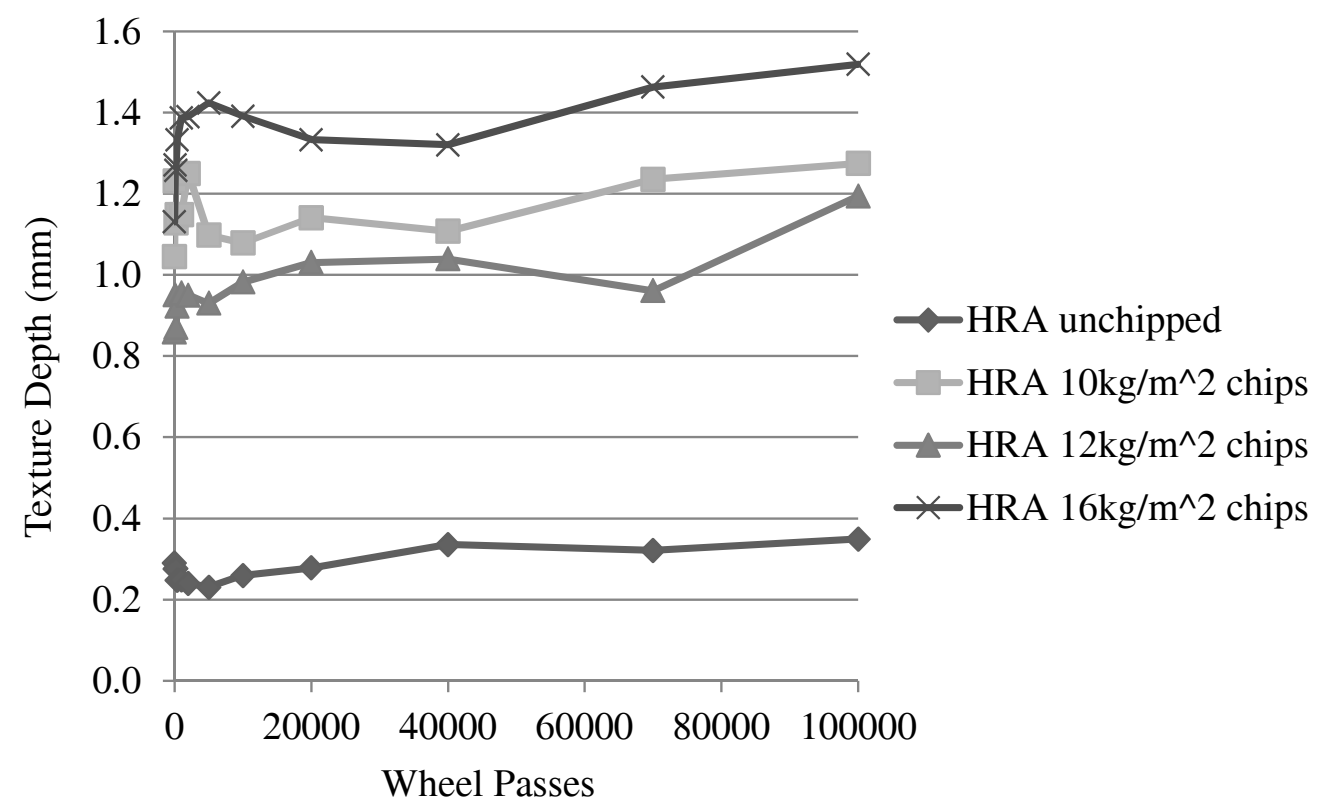

Figure 10. Development of texture depth for HRA - sand patch data 
In contrast, the $20 \mathrm{~mm}$ chippings are lightly coated in a low pen grade binder that would be much easier to remove under trafficking so exposing the aggregate micro-texture. The maximum PTV values are comparable for both mix types. After reaching maximum PTV the unchipped HRA maintains the highest level of PTV. This is explained by the rough sand-paper type texture that develops on the HRA mortar during trafficking. This is similar to high PTV values measured for HFS that using a $3 \mathrm{~mm}$ aggregate. However, in-service unchipped HRA because it has almost no macro-texture has low SCRIM and GripTester values i.e. there is limited ability to disperse the water film that is generated under the test tyre of both devices as they test at 30mph. This conflict between laboratory and in-service data shows the importance of engineering judgement and experience when considering just laboratory based data. The texture depth data plotted in Figure 8 shows the relationship for chipping application rate. The small increase in texture with time relates to surface wear and ravelling of chippings.

\section{CONCLUSIONS}

All the test data given in this paper was obtained using the RTM equipment under the same controlled laboratory conditions. Unlike other test equipment such as PSV and Wehner Schulze, the RTM uses 2 full-scale tires to traffic test specimens in the same way every time. This allows different materials to be ranked using different measured properties. The data plotted in Figure 4 shows the range of laboratory measured PTV achieved for materials typically used in Ireland and the UK. Simplified groupings of data in Figures 5 and 6 show how skid resistance and texture depth can be related to both rock type and mix type. The rankings achieved in the laboratory using the RTM relate to what is measured in-service using devices such as SCRIM and GripTester. Figure 7 shows how wet skid resistance can be optimised for an aggregate by using it in different nominal sized mixes. Figure 9 shows the same optimisation for Hot Rolled Asphalt and the application of pre-coated chippings. The values for unchipped HRA show how caution and engineering judgement is important.

Both PSV and Wehner Schulze attempt to predict wet skid resistance. However, this is the only property that these methods predict. In contrast, RTM testing subjects the test specimen to trafficking using full-scale tires rather than solid rubber tires / rollers. This real interaction between tire and surface of the $305 \times 305 \mathrm{~mm}$ test specimens gives a trafficked area large enough for other forms of measurement. In this paper only texture depth using sand patch is considered. Figures 8 and 10 show how the texture depth of the SMA and HRA test specimens develop during simulated trafficking. The values of the laboratory prepared test specimens are similar to what would be expected in-service. With trafficking, these typically show small changes in texture during early life after which it remains relatively unchanged. This was more apparent for the SMA mixes i.e. they achieved equilibrium and stayed there reflecting a durable long lasting mix. In contrast, the chipped HRA showed small increases in texture reflecting the on-set of ravelling or chipping loss. 
RTM testing allows measurement of other properties. Current research at University of Ulster is looking at the removal of bitumen coatings to expose aggregate micro-texture using image analysis techniques. The role of $3 \mathrm{D}$ texture at the micro-scale level on aggregate particles to the macro-scale level of the asphalt mix is possible using close range photogrammetry and laser based techniques. The development of contact area and pressure distribution is possible using pressure mapping systems. Although these techniques are not included in this paper, they represent some of the methods that will be used in the future to determine how the engineering properties of highway surfacing materials can be better measured leading to improved understanding of performance and optimised.

\section{ACKNOWLEDGEMENTS}

The research presented in this paper was funded by the National Roads Authority of Ireland through the NRA Research Fellowship Programme. The views expressed are not necessarily those of the National Roads Authority.

\section{REFERENCES}

BBA, 2008. Guidelines document for the assessment and certification of high friction surfacing for highways, Watford: British Board of Agrement.

BBA, 2011. BBA Datasheet No. 04/06. The Highway Authorities Product Approval Scheme (HAPAS). [Online] Available at: http://www.bbacerts.co.uk [Accessed 17 November 2012].

BSI, 2000. Surface friction of pavements - Part 2: Test method for measurement of surface skid resistance using the Grip Tester braked wheel fixed slip device. London: British Standards Institution.

BSI, 2006. Methods for measuring the skid resistance of pavement surfaces - Part 1: Sideway-force coefficient routine investigation machine, London: British Standards Institution.

DMRB, 2004. Skid Resistance; HD 28/04; Design Manual for Roads and Bridges; Vol. 7, Section 3, Part 1, London: Highways Agency.

Nicholls, J., 1997. Laboratory tests on high friction surfaces for highways, TRL Report 176, s.1.: Transport Research Laboratory.

NRA, 2011a. NRA Design manual for roads and bridges. Volume 7.3.1 Pavement design and maintenance. NRA HD 28/11. Management of skid resistance, Dublin: National Roads Authority.

NSAI, 2006a. IS EN 13108-1:2006. Bituminous Mixtures - Material Specifications Part 1: Asphalt Concrete, Dublin: National Standards Authority of Ireland.

NSAI, 2006b. IS EN 13108-4:2006. Bituminous Mixtures - Material Specifications Part 4: Hot Rolled Asphalt, Dublin: National Standards Authority of Ireland.

NSAI, 2006c. IS EN 13108-5:2006. Bituminous Mixtures - Material Specifications Part 5: Stone Mastic Asphalt, Dublin: National Standards Authority of Ireland. 
NSAI, 2009b. IS EN 1097-8:2009. Tests for mechanical and physical properties of aggregates. Part 8: Determination of the polished stone value, Dublin: National Standards Authority of Ireland.

NSAI, 2010b. IS EN 13036-1:2010. Road and airfield surface characteristics - Test methods - Part 1: Measurement of pavement surface macrotexture depth using a volumetric patch technique, Dublin: National Standards Authority of Ireland.

NSAI, 2011c. IS EN13036-4:2011. Road and airfield surface characteristics. Test methods. Method for measurement of slip/skid resistance of a surface. The pendulum test, Dublin: National Standards Authority of Ireland.

Roe, P., Dunford, A. \& Crabb, G., 2008. HA/QPA/RBA Collaborative Programme 2004/07: Surface requirements for asphalt roads, Published Project Report PPR324, Crowthorne: TRL Limited.

Roe, P. G. \& Hartshorne, S. A., 1998. The Polished Stone Value of aggregates and in-service skidding resistance, Berkshire, U.K.: Transport Research Laboratory.

Roe, P. G. \& Lagarde-Forest, R., 2005. The Early Life Skid Resistance of Asphalt Surfaces. TRL Published Project Report PPR060, Berkshire, UK: Transport Research Laboratory.

Thompson, A., Burrows, A., Flavin, D. \& Walsh, I., 2004. The Sustainable Use of High Specification Aggregates for Skid Resistant Road Surfacing in England. Report to the Office of the Deputy Prime Minister and the Mineral Industry Research Organisation, East Grinstead: Capita Symonds Ltd.

Woodbridge, M. \& Dunford, A. R. P., 2006. Wehner-Schulze machine: First UK experiences with a new test for polishing resistance in aggregates. Published Project Report PPR144, Crowthorne: TRL Limited. 